\title{
Risk factors for avascular necrosis of bone in patients with systemic lupus erythematosus: Is there a role for antiphospholipid antibodies?
}

\author{
M Y Mok, V T Farewell, D A Isenberg
}

\begin{abstract}
Background-Avascular necrosis of bone (AVN) is a well known complication in patients with systemic lupus erythematosus (SLE).

Objective-To investigate the role of antiphospholipid antibody status (IgM and IgG anticardiolipin antibodies and lupus anticoagulant) with adjustment for corticosteroid use as risk factors for the development of AVN.

Methods-A cohort of 265 patients receiving long term follow up in our SLE clinic from 1978 to 1998 was analysed. Patients with AVN complications were detected and then matched for age, sex, ethnicity, duration of disease, and organ disease with two other patients with SLE. A further 31 patients were chosen at random for the analysis.

Results-Eleven patients had AVN, giving a point prevalence of $4 \%$. There were no significant differences demonstrable in the presence of individual antiphospholipid antibodies (aPL) or their combination between the group with AVN or the two control groups.

Conclusion-Incorporating an adjustment for corticosteroid use we were unable to show a link between the presence of aPL and the development of AVN in patients with SLE.

(Ann Rheum Dis 2000;59:462-467)
\end{abstract}

Bloomsbury

Rheumatology Unit, University College

London Medical

School, London

M Y Mok

D A Isenberg

Department of

Statistical Science,

University College

London Medical

School, London

V T Farewell

Correspondence to: Dr M Y Mok, University Department of Medicine, Division of Rheumatology, 4/F Professorial Block, Queen Mary Hospital, Pokfulam Road, Hong Kong Email: mymok@ netvigator.com

Accepted for publication 22 November 1999

Systemic lupus erythematosus (SLE) is an autoimmune rheumatic disease that affects young women, resulting in significant morbidity and mortality. Avascular necrosis of bone (AVN) is a well recognised complication of SLE, which also results in significant morbidity. The clinical course is usually progressive to end stage secondary degenerative changes of the joint causing significant pain and limitation of movement, and reducing the quality of life in these young patients. Histologically, this condition is characterised by subchondral bone necrosis as a result of compromise of end traumatic causes of the arterial interruption that lead to AVN development in SLE have been looked into in the past two decades. Corticosteroid treatment is considered an important risk factor, ${ }^{1-5}$ but there are reports of patients with SLE complicated by AVN who had never been receiving steroid. ${ }^{6}{ }^{7}$ Intrinsic vascular factors related to SLE-like vasculitis and vasculopathy have been proposed, and Raynaud's phenomenon has been reported to be associated with AVN development. ${ }^{58}$ In addition, the presence of antiphospholipid antibodies (aPL), a potential risk factor for vascular thrombosis, has been proposed to predispose towards AVN but its role remains controversial. We performed a retrospective case-control study to look into the risk factors, in particular aPL and corticosteroid use, for the development of AVN.

\section{Methods}

SELECTION OF INDEX PATIENTS AND CONTROL GROUPS

Records of the cohort of patients with SLE who have attended our lupus clinic at UCL/Middlesex from 1978 to 1998 for a minimum of two years or until death were reviewed, and patients who developed AVN were identified. All patients fulfilled the 1982 revised American Rheumatic Association criteria for the classification of SLE. Index patients with AVN were symptomatic and had the diagnosis of AVN made from plain radiography, bone scan, and/or magnetic resonance imaging scan.

Two control groups were selected. The first comprised two patients with SLE without AVN carefully matched to each of our index patients for age, sex, race, duration of symptoms, age of onset, and organ disease (that is, 22 matched controls). The second control group consisted of patients with SLE selected randomly (that is, artery supply to the bone. Various non-
31 unmatched controls).

DEMOGRAPHIC DATA AND CLINICAL FEATURES The demographic data of these patients (including their age at study, sex, ethnicity, age at onset of SLE, age at diagnosis of AVN, duration between onset of SLE and diagnosis of AVN), other major systemic manifestations of SLE, autoantibody profile (including antinuclear antibodies, anti-dsDNA, extractable nuclear antigen antibodies, aPL including IgM and IgG anticardiolipin antibodies (aCL), and lupus anticoagulant (LAC), activated partial thromboplastin time), other major systemic illnesses, smoking, and drinking habits were recorded.

For patients with AVN, sites of articular disease affected by AVN and information on surgical interventions were recorded. Any bone 


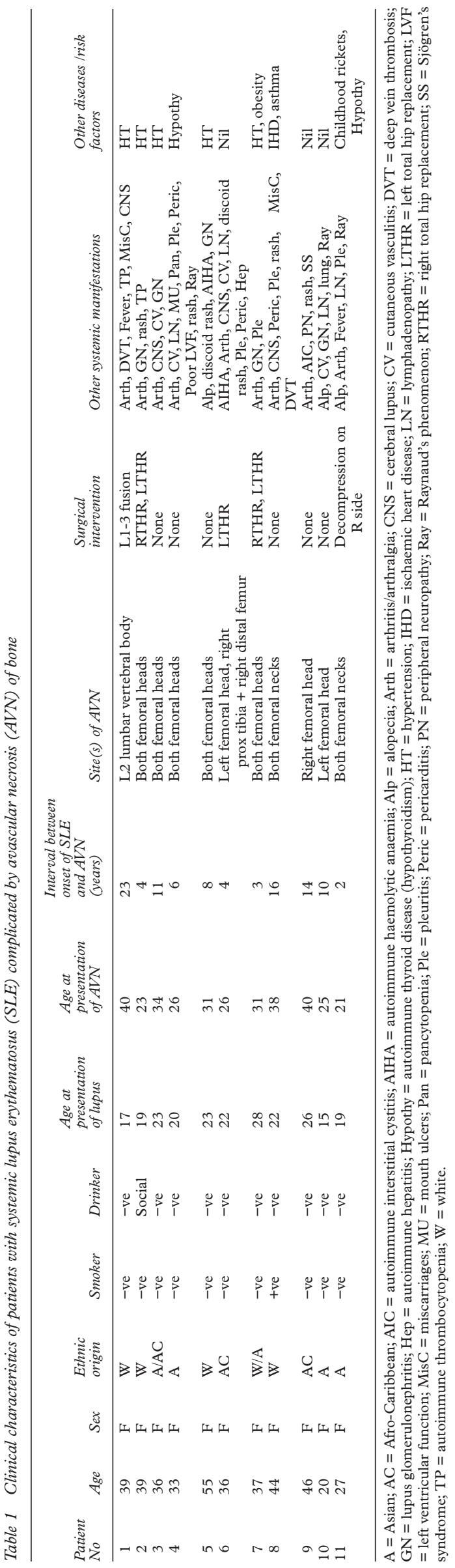

mineral density measurement performed at around the time of the development of AVN was also noted. Daily and total cumulative dose of corticosteroid at the development of AVN were calculated as a prednisolone equivalent.

STATISTICAL ANALYSIS

To accommodate the $2: 1$ matching in this study, the comparison of the patients with AVN with their matched controls was based on conditional logistic regression. This methodology models the probability of AVN as a function of explanatory variables after adjusting for characteristics common to the matched sets. The variables defined were binary indicators of $\operatorname{IgM}$ and $\operatorname{IgG}$ aCL, a binary indicator for LAC, and a variable which coded cumulative steroid dose. The results of the logistic analyses are summarised as an odds ratios (OR). For a simple binary classification, such as the presence or absence of LAC, an OR compares the odds of AVN for a patient in one class, say those having LAC, with the odds for other patients.

For a continuous measure such as steroid dose, the OR compares the odds of AVN for two patients whose steroid doses differ by one unit. If patients' times differed by, say, $\mathrm{k}$ units, then their odds of AVN would be related by a factor of $(\mathrm{OR})^{\mathrm{k}}$. The inclusion of steroid dose in the models was undertaken to provide a comparison of aPL status, which was adjusted for any differences in steroid use between the matched pairs that remain after matching for disease duration. The study was not designed to provide a detailed investigation of the effect of steroid use.

The comparison of patients with AVN with the unmatched control group was based on unconditional logistic regression as there is no matching to be considered. The analysis is otherwise similar to that for the matched controls except that an additional adjustment variableage of SLE diagnosis-was included.

\section{Results}

Eleven patients with SLE from our cohort of 265 were found to have AVN complications, giving a point prevalence of $4 \%$. Table 1 summarises the demographic data and clinical features of these patients and table 2 shows their serological characteristics. Their mean age at the time of study was 37.9 (range 27-55) years. All patients were female. Four were white, three Asian, two Afro-Caribbean, and two of mixed ethnicity (one Asian/Afro-Caribbean and the other Asian/white).

The mean age of onset of SLE was 21.3 (range 17-28) years and the mean age of presentation of AVN was 30.5 (range 21-40) years. The average interval between the onset of SLE and the diagnosis of AVN was 9.2 (range 2-23, median 6) years. The femoral head was the most commonly affected site $(10 / 11,91 \%)$ and often affected both femoral heads (7/10, 70\%). Patient 1 had AVN affecting an isolated lumbar vertebra (L2), and in another patient (No 6) more than one site-left femoral head, right 
Table 2 Serological characteristics and previous steroid use in patients with systemic lupus erythematosus (SLE) complicated by avascular necrosis $(A V N)$ of bone

\begin{tabular}{|c|c|c|c|c|c|c|c|c|c|c|c|c|}
\hline $\begin{array}{l}\text { Patient } \\
\text { No }\end{array}$ & $A N A$ & $R F$ & $D N A$ & $E N A$ & $a C L$ & $L A C$ & $A P T T$ & $\begin{array}{l}\text { Lymphocyte } \\
\text { count }\end{array}$ & Platelet count & $B M D$ & $\begin{array}{l}\text { Daily dose of } \\
\text { prednisolone } \\
\text { equivalent ( } m g) \text { at } \\
\text { diagnosis of } A V N\end{array}$ & $\begin{array}{l}\text { Cumulated dose of } \\
\text { prednisolone } \\
\text { equivalent (mg) at } \\
\text { diagnosis of } A V N\end{array}$ \\
\hline 1 & $1 / 2560$ & $-\mathrm{ve}$ & +ve & $-\mathrm{ve}$ & $\operatorname{IgG}$ & +ve & Prolong & Low & Low & Slightly low & 5 & 37730 \\
\hline 2 & $1 / 2560$ & - ve & - ve & Ro & $\operatorname{IgM}$ & - ve & Normal & Low & Low & Normal & 0 & 11200 \\
\hline 3 & $1 / 640$ & -ve & +ve & RNP & $-\mathrm{ve}$ & $-\mathrm{ve}$ & Normal & Low & Normal & Normal & $\begin{array}{l}10 \text { CTX, } \\
\text { 3-monthly }\end{array}$ & 46588 \\
\hline 4 & $1 / 160$ & + ve & -ve & RNP & $\operatorname{IgM}$ & $-\mathrm{ve}$ & Normal & Low & Normal & $\mathrm{ND}$ & 5 & 16800 \\
\hline 5 & $>1 / 1280$ & $+\mathrm{ve}$ & $+\mathrm{ve}$ & - ve & $-\mathrm{ve}$ & - ve & Normal & Low & Normal & Normal & 7.5 & 32060 \\
\hline 6 & $1 / 1280$ & $+\mathrm{ve}$ & +ve & Sm, Ro & $-\mathrm{ve}$ & - ve & Normal & Low & Slightly low & Normal & 5 & 21586 \\
\hline 7 & $1 / 160$ & $-\mathrm{ve}$ & + ve & $\mathrm{Sm}$ & $\mathrm{IgG}$ & $-\mathrm{ve}$ & Normal & Low & Normal & ND & 10 & 7290 \\
\hline 8 & $1 / 5120$ & $-\mathrm{ve}$ & +ve & Ro,La & IgG & +ve & Normal & Low & Normal & ND & 0 & 50205 \\
\hline 9 & $1 / 320$ & - ve & $-\mathrm{ve}$ & Ro & - ve & $-\mathrm{ve}$ & Normal & Low & Normal & Normal & 4 & 26789 \\
\hline 10 & $1 / 10240$ & - ve & +ve & $-\mathrm{ve}$ & $-\mathrm{ve}$ & - ve & Prolong & Low & Normal & ND & 5 & 37391 \\
\hline 11 & $>1 / 1280$ & $-\mathrm{ve}$ & +ve & Ro, La, RNP & - ve & - ve & Normal & Low & Normal & ND & 7.5 & 4760 \\
\hline
\end{tabular}

ANA = antinuclear antibody (tested on Hep 2 cells); APTT = activated partial thromboplastin time; BMD = bone mineral density; CTX = cyclophosphamide; DNA $=$ anti-dsDNA (tested on Crithidia lucidiae); ENA = antibodies to extractable nulcear antigens (tested by ELISA); LAC = lupus anticoagulant; RF = rheumatoid factor; $(\mathrm{w})=$ weak.

distal femur, and right rib-was affected. All these patients were symptomatic at the diagnosis of their AVN and the diagnosis was confirmed by magnetic resonance imaging of the affected region. Three patients $(2,6,7)$ needed total hip replacement surgery and one received decompression surgery to her right hip (11).

Other major organ disease of their underlying SLE included glomerulonephritis in 5/11 $(45 \%)$, pleuritis in $5 / 11(45 \%)$, cutaneous vasculitis in 4/11 (36\%), lymphadenopathy in 4/11 $(36 \%)$, cerebral lupus in $4 / 11(36 \%)$, and pericarditis in $3 / 11(27 \%)$. Raynaud's phenomenon was found in $3 / 11(27 \%)$ patients. All patients had lymphopenia and two patients had significant thrombocytopenia.

Patients 1 and 8 had clinical features of secondary antiphospholipid syndrome (APS). Both had recurrent deep vein thrombosis, recurrent miscarriages and central nervous system manifestations (patient 1 had migrainous headache, patient 8 had diplopia and limb weakness). All patients had positive antinuclear antibodies. Eight of $11(73 \%)$ patients had positive anti-dsDNA antibodies during any stage of their lupus presentation. Anti-Ro antibodies were found in 5/11 (45\%) patients, anti-RNP in 3/11 (27\%) patients while anti-La and anti-Sm were both found in $2 / 11(18 \%)$ patients. Anti-ENA antibodies were not present in three patients.

Two of $11(18 \%)$ patients had positive IgM aCL, 3/11 (27\%) patients had positive IgG aCL, and $2 / 11(18 \%)$ patients had positive LAC (table 3). Two patients had prolonged activated partial thromboplastin time. Five of $11(45 \%)$ patients had coexisting hypertension and $2 / 11(18 \%)$ patients had hypothyroidism on thyroxine replacement with stable and normal thyroid function tests. All patients with concomitant systemic hypertension were prescribed antihypertensive drugs, and three had fair control, needing frequent readjustment of their treatment. None of the patients had sickle cell trait or disease. Only one patient in our series was a chronic smoker and none of them was a heavy drinker. The bone mineral density around the time of diagnosis of AVN was available in six patients, and five of them $(83 \%)$ were unremarkable. The mean daily dose of corticosteroid at the time of diagnosis of AVN was 5.4 (range $0-10$ ) $\mathrm{mg}$. Two patients (2 and 8 ) had already had their corticosteroids reduced and were receiving azathioprine maintenance alone. One patient was receiving a third course of three-monthly intravenous cyclophosphamide infusions for her lupus nephritis. Proteinuria was improving and there was no other clinical evidence of active lupus. The mean total cumulative corticosteroid doses, as prednisolone equivalents, were $26.6 \mathrm{~g}, 21.8 \mathrm{~g}$, and $27.2 \mathrm{~g}$ for patients with AVN, and the matched and unmatched control groups respectively. Note, that as might be expected for patients matched for disease severity, there was no significant difference in total cumulative corticosteroid dose between the AVN group and their matched controls $(p=0.38)$ or between the AVN group and the unmatched controls $(\mathrm{p}=0.92)$.

Table 3 presents the results of including the three binary indicators for IgM, IgG aCL, and LAC, separately and together, in logistic regression models based on the matched and

Table 3 Logistic regression analysis on contribution of antiphospholipid antibodies (aPL), singly or in combination, to the development of avascular necrosis ( $A V N$ )

\begin{tabular}{|c|c|c|c|c|c|c|c|c|c|c|c|}
\hline \multirow[b]{3}{*}{$a P L$} & \multirow{3}{*}{$\begin{array}{l}\text { AVN group } \\
\text { No }(\%)\end{array}$} & \multicolumn{5}{|c|}{ Matched controls ${ }^{\star}$} & \multicolumn{5}{|c|}{ Unmatched controlst } \\
\hline & & \multirow[b]{2}{*}{ No (\%) } & \multicolumn{2}{|c|}{ Univariate } & \multicolumn{2}{|c|}{ Multivariate } & \multirow[b]{2}{*}{ No (\%) } & \multicolumn{2}{|c|}{ Univariate } & \multicolumn{2}{|c|}{ Multivariate } \\
\hline & & & $O R$ & $p$ Value & OR & $p$ Value & & OR & $p$ Value & $O R$ & $p$ Value \\
\hline $\operatorname{IgM} \mathrm{aCL}$ & $2 / 11(18)$ & $3 / 22(14)$ & 1.24 & 0.82 & 1.40 & 0.38 & $3 / 31(10)$ & 2.28 & 0.54 & 2.11 & 0.59 \\
\hline $\mathrm{IgG}$ aCL & $3 / 11(27)$ & $6 / 22(27)$ & 1.32 & 0.74 & 1.57 & 0.73 & $9 / 31(29)$ & 1.62 & 0.63 & 1.34 & 0.84 \\
\hline LAC & $2 / 11$ (18) & $5 / 22(23)$ & 0.99 & 0.99 & 1.57 & 0.80 & $4 / 31$ (13) & 2.01 & 0.60 & 1.32 & 0.89 \\
\hline
\end{tabular}

*Adjusted for cumulative steroid dose.

tAdjusted for cumulative steroid dose and age of SLE diagnosis.

$\mathrm{aCL}=$ anticardiolipin antibodies; $\mathrm{LAC}=$ lupus anticoagulant; $\mathrm{OR}=$ odds ratio. 
Table 4 English literature search 1960-98: cross sectional or prospective studies on antiphospholipid antibodies (aPL) and avascular necrosis (AVN)

\begin{tabular}{|c|c|c|c|c|c|c|c|}
\hline Authors (reference) & $\begin{array}{l}\text { Patients with } \\
\text { SLE studied (n) }\end{array}$ & $\begin{array}{l}\text { Prevalence of } \\
\text { AVN (\% (No)) }\end{array}$ & aPL tested & $\begin{array}{l}\text { Prevalence of APL in } \\
\text { patients with } A V N \\
(\%(\text { No) })\end{array}$ & $\begin{array}{l}\text { Prevalence of APL in } \\
\text { control group (\% (No)) }\end{array}$ & $\begin{array}{l}\text { Association of } \\
\text { APL with } A V N\end{array}$ & $\begin{array}{l}\text { Concomitant } \\
\text { corticosteroid } \\
\text { use }\end{array}$ \\
\hline Nagasawa et $a l^{24}$ & 111 & $22(24 / 111)$ & $\begin{array}{l}\text { LAC } \\
\text { LAC + shorten aPTT }\end{array}$ & $\begin{array}{l}25(6 / 24) \\
54(13 / 24)\end{array}$ & $\begin{array}{l}5(11 / 44) \\
23(10 / 44)\end{array}$ & $\begin{array}{l}\text {-ve } \\
+ \text { ve }(\mathrm{p}<0.05)\end{array}$ & $+\mathrm{ve}$ \\
\hline Alarcon-Segovia et al ${ }^{25}$ & 500 & $6(28 / 500)$ & $\mathrm{aCL}$ & NS & NS & - ve & $+\mathrm{ve}$ \\
\hline Asherson et al ${ }^{30}$ & 800 & $5(37 / 800)$ & LAC and aCL & $73(27 / 37)$ & $\begin{array}{l}\text { No control group } \\
\text { analysed }\end{array}$ & $\begin{array}{l}\text { No statistics } \\
\text { provided }\end{array}$ & $+\mathrm{ve}$ \\
\hline Migliaresi et al $^{23}$ & $(69$ & $10(7 / 69)$ & $\mathrm{aCL}$ & $29(2 / 7)$ & $39(24 / 62)$ & $-\mathrm{ve}$ & +ve \\
\hline Mok et al ${ }^{26}$ & 320 & $12(38 / 320)$ & $\begin{array}{l}\text { LAC } \\
\text { IgG aCL } \\
\text { IgM aCL }\end{array}$ & $\begin{array}{l}27(9 / 33) \\
42(15 / 36) \\
8(3 / 36)\end{array}$ & $\begin{array}{l}12(16 / 139) \\
52(74 / 142) \\
5(7 / 142)\end{array}$ & $\begin{array}{l}\text { +ve }(p=0.02) \\
\text {-ve } \\
\text {-ve }\end{array}$ & $+\mathrm{ve}$ \\
\hline
\end{tabular}

$\mathrm{aCL}=$ anticardiolipin antibodies; $\mathrm{LAC}=$ lupus anticoagulant; SLE $=$ systemic lupus erythematosus.

unmatched controls. Also displayed are the number of patients in the various groups with aCL and LAC. It can be seen that the number of patients with the antibodies and LAC is comparable in the various groups and indeed the overall frequency is relatively small. The formal analysis confirms that there is no evidence of any relation between these indicators and the presence of AVN. In addition, a test for the effect of having one or more of the two antibodies and LAC was not significant, with a significance level of 0.64 based on the matched controls and a significance level of 0.17 based on the unmatched controls.

\section{Discussion}

AVN is a well described complication of SLE. Dubois and Cozen were among the first authors to describe this condition in association with SLE in $1960 .{ }^{6}$ There have been many subsequent descriptions of AVN, but many reports that evaluated the proposed risk factors for its development in SLE failed to show consistent results supporting an association. Potential risk factors include corticosteroid use, ${ }^{1-5}$ vasculitis, ${ }^{9} 10$ Raynaud's phenomenon, ${ }^{58}$ and the presence of aPL. Our case-control study aimed at elucidating the role, if any, of the presence of aPL.

The point prevalence of AVN in our cohort is $4 \%$, at the lower end of the reported incidence, which has ranged from 4 to $9 \% .{ }^{11}$ Our data, however, may be an underestimate as AVN was diagnosed in symptomatic patients only. It is interesting to note that patient 1 developed AVN in an isolated L2 vertebral body without evidence of disease elsewhere. This was an unusual presentation of AVN. Egan and Munn reported on another patient who presented with catastrophic APS and acute onset of AVN affecting multiple sites that included T8, L4, and L5 vertebral bodies. ${ }^{12}$ Our patient 6 also had multiple sites affected. There have been a number of reports about AVN affecting as many as 13 sites in a lupus patient. $^{12-14}$

Corticosteroids have long been regarded as a risk factor for the development of AVN. The histology of AVN is characterised by subchondral bone necrosis that occurs as a result of ischaemic injury. The vascular compromise could be attributed to a steroid induced hypercoagulative state, ${ }^{15}{ }^{16}$ abnormal lipid metabolism as a result of corticosteroid use, or fat embolism. ${ }^{17}{ }^{18}$ Moreover, hypertrophy of fat cells ${ }^{13}$ has been postulated to result in an increase in intraosseous pressure, which has been shown to compromise the arterial supply to the bone further. ${ }^{20}$

Corticosteroid use was invariably found in patients with SLE who developed AVN, with a few exceptions. In a meta-analysis of 22 papers, a strong correlation between oral steroid dose and incidence of AVN was found, whereas the bolus dose was not associated with AVN. ${ }^{21}$ On the other hand, De Graaf et al found that the total amount of prednisone given during the first months after transplantation was critical for the development of AVN. ${ }^{22}$ This issue had been evaluated by Migliaresi et al, who found no difference in the highest corticosteroid intake for a single month, for 3, 6, and 12 consecutive months and the total corticosteroid intake between lupus patients with $\mathrm{AVN}$ and those without. ${ }^{23}$ In our study all patients with AVN had been treated with corticosteroids. Although not the primary focus of our study, we found no difference in the cumulative corticosteroid use between patients with AVN and unmatched controls.

Table 5 English literature search 1960-98: case reports of avascular necrosis (AVN) in primary or secondary antiphospholipid syndrome (APS)

\begin{tabular}{|c|c|c|c|c|c|c|c|}
\hline Authors (reference) & 1/ or $2 / A P S$ & Age & Sex & Race & Site (s) of osteonecrosis & $\begin{array}{l}\text { Previous } \\
\text { corticosteroid use }\end{array}$ & Remarks \\
\hline Alijotas $e t a l^{9}$ & 1/ & 32 & $\mathrm{~F}$ & W & Lunate & $-\mathrm{ve}$ & \\
\hline Vela et $a b^{\beta 1}$ & $1 /$ & 32 & $\mathrm{~F}$ & W & Left femoral head & $-v e$ & \\
\hline Seleznick et $a b^{2}$ & $1 /$ & 47 & $\mathrm{~F}$ & AC & Left femoral head, right knee & $-\mathrm{ve}$ & \\
\hline Egan $e t a l^{12}$ & $1 /$, catastrophic & 25 & $\mathrm{~F}$ & $\mathrm{~W}$ & $\begin{array}{l}\text { Proximal femur, T8, L4, L5 } \\
\text { vertebrae, manubrium, lower } \\
\text { sternum, (shoulders, elbows, } \\
\text { wrists, ankles, tibiae) }\end{array}$ & -ve & $\begin{array}{l}1 \text { month after hysterectomy for } \\
\text { carcinoma of uterus, } \\
\text { concomitant AIHA, leg ulcer, } \\
\text { and RTA (IV) }\end{array}$ \\
\hline
\end{tabular}


It is difficult to determine whether corticosteroid treatment itself, or the severity of underlying lupus, is directly implicated in the development of AVN as most patients with active disease are treated with corticosteroids. Vasculitis or other factors may account for the very few reports of patients with SLE with AVN who had not received corticosteroids. ${ }^{67}$ The data in our study, like that reported by Nagasawa et $a l,{ }^{24}$ showed that a relatively small daily dose of corticosteroid was being used $(5.4 \mathrm{mg}$ ) and that clinical disease was relatively inactive when AVN was diagnosed. Raynaud's phenomenon, which has been proposed to be associated with AVN in some reports ${ }^{67}$ but not others, ${ }^{25}$ was present in three of our patients with AVN and six matched patients, with no difference demonstrable $(\mathrm{p}=0.99)$.

Whether aPL are present as "bystanders" in lupus patients with AVN or whether they are directly responsible for this condition remains controversial. Their prothrombotic potential suggests that aPL might predispose to AVN by causing microvascular thrombosis. In fact, thrombosis of terminal arteries in subchondral bone was identified in histological findings in non-traumatic AVN in one study $^{27}$ but not in another. ${ }^{28}$ Table 4 shows the various authors reporting an association between aPL and the development of AVN. ${ }^{23-2630}$ The reported prevalence of aPL among patients with SLE with AVN ranged from 8 to $73 \%$, depending on which aPL were measured. Some groups found an association when compared with lupus patients without AVN complications, but some did not. This discrepancy may be accounted for by the concomitant use of corticosteroids in these patients. None of these patients with positive aPL had clinical features of secondary APS.

There are a number of reports on patients with primary APS who had not had corticosteroid treatment before and had AVN complications (table 5). These cases may suggest a role for aPL in predisposition to AVN. Alijotas et al found three of 16 patients with Kienbock's disease (AVN of lunate bone) ${ }^{29}$ One patient had clinical features suggestive of primary APS but only a modestly raised IgM aCL. The contralateral lunate bone was affected six months later. The other two patients had no previous thrombotic episodes but both had positive LAC. One patient had borderline raised IgM aCL and the other IgG aCL. In a larger scale study by Asherson et al of 70 patients satisfying the criteria for primary APS, only two (2.9\%) were identified with AVN. ${ }^{30}$ In one of these patients, AVN was the initial presentation of his primary APS in the absence of previous steroid treatment. Two patients with SLE with secondary APS in our study had AVN complications and another four patients had serologically positive aPL without any clinical symptoms. No association could be found between aPL or their combination and development of AVN.
The role of aPL in predisposition to AVN remains controversial. We carefully selected two matched controls for each patient with SLE complicated by AVN matched for age, sex, ethnicity, duration of disease, and severity of disease. We also specifically adjusted for corticosteroid use, though no significant difference was found between the total cumulative dose of corticosteroid between patients with AVN and the matched control group. Our results showed that there was no relation between IgM aCL, IgG aCL, LAC, or their combination and the development of AVN.

In summary, our data using carefully matched groups to permit us to allow for a variety of patient factors have failed to reveal a role for aPL in the development of AVN in patients with SLE. Other, as yet unidentified factors, or a combination of factors, may cause this significant damaging effect in these patients.

1 Harrington KD, Murray WR, Kountz SL, Belzer FD. Avascular necrosis of bone after renal transplantation. J Bone Joint Surg Am 1971;53:203-15.

2 Murray WR. Hip problems associated with organ transplants. Clin Orthop 1973;90:57-69.

3 Heimann WG, Freiberger RH. Avascular necrosis of the femoral and humeral heads after high dosage corticosteroid therapy. N Engl J Med 1960;263:672-5.

4 Abeles M, Urman JD, Rothfield NF. Aseptic necrosis of bone in systemic lupus erythematosus. Relationship to corticosteroid therapy. Arch Intern Med 1978;138: $750-4$.

5 Zizic TM, Marcoux C, Hungerford DS, Dansereau JV, Stevens MB. Corticosteroid therapy associated with ischemic necrosis of bone in systemic lupus erythematosus. Am J Med 1985;79:596-604.

6 Dubois EL, Cozen L. Avascular (aseptic) bone necrosis associated with systemic lupus erythematosus. JAMA 1960;174:966-71.

7 Leventhal GH, Dorfman HD. Aseptic necrosis of bone in systemic lupus erythematosus. Semin Arthritis Rheum 1974:4;73-93.

8 Klipper AR, Stevens MB, Zizic TM, Hungerford DS. schemic necrosis of bone in systemic lupus erythematosus. Medicine (Baltimore) 1976;55:251-7.

9 Mont MA, Glueck CJ, Pacheco IH, Wang P, Hungerford DS, Petri M. Risk factors for osteonecrosis in systemic lupus erythematosus. J Rheumatol 1997;24:654-62.

10 Velayos EE, Lordholt JD, Smyth CJ. Arthroplasty associated with steroid therapy. Ann Intern Med 1966;64: 759-71.

11 Wallace DJ. The musculoskeletal system: Avascular necrosis of bone. In: Wallace DJ, Hahn BH, eds. Dubois's lupus eryhematosus. 5th ed. Los Angeles: Williams \& Wilkins. 1997: $641-5$.

12 Egan RM, Munn RK. Catastrophic antiphospholipid antibody syndrome presenting with multiple thromboses and sites of avascular necrosis. J Rheumatol 1994;21: 2376-9.

13 Ruderman M, McCarty DJ Jr. Aseptic necrosis in systemic lupus erythematosus. Report of a case involving six joints. Arthritis Rheum 1964;7:709-21.

14 Darlington LG. Osteonecrosis at multiple sites in a patient with systemic lupus erythematosus. Ann Rheum Dis 1985; 44:65-6.

15 Cosgriff WW. Thromboembolic complications associated with ACTH and cortisone therapy. JAMA 1951;147: 924-6.

16 Goldie I, Tibblin G, Scheller S. Systemic lupus erythematosus and aseptic bone necrosis. Acta Med Scand 1967;182: $55-6$

17 Jones JP, Engelman EP, Najarian JS. Systemic fat embolism after renal homotransplantation and treatment with corticosteroids. N Engl J Med 1965;273:1453-8

18 Fisher DE, Bickel WH, Holley KE. Histologic demonstration of fat emboli in aseptic necrosis associated with hypercortisone. Mayo Clin Proc 1969;44:252-9.

19 Smith FE, Sweet DE, Brunner CM, Davis JS. Avascular necrosis in SLE. An apparent predilection for young patients. Ann Rheum Dis 1976;35:227-32.

20 Jaffe HL. Ischemic necrosis of bone. Medical Radiography and Photography 1969;45:58-86.

21 Felson DT, Anderson JJ. A cross-study evaluation of association between steroid dose and bolus steroids and avascular necrosis of bone. Lancet 1987;1:902-5.

22 De Graaf P, van Hooff JP, Boekhout M, Achterberg J, Pauwell EK, Kalff MW. Hyperparathyroidism and avascular necrosis of bone after kidney transplantation. A retrospecnecrosis of bone after kidney transplantation. A retrospec-
tive study of 170 transplant recipients. Neth J Med tive study of 170 
23 Migliaresi S, Picillo U, Ambrosone L, Di Palma G, Mallozzi M,Tesone ER, et al. Avascular osteonecrosis in patients
with SLE: relation to corticosteroid therapy and anticardiwith SLE: relation to corticosteroid the
olipin antibodies. Lupus 1994;3:37-41

24 Nagasawa K, Ishii Y, Mayumi T, Tada Y, Ueda A, Yamauchi $\mathrm{Y}$, et al. Avascular necrosis of bone in systemic lupus erythematosus: possible role of haemostatic abnormalities. Ann Rheum Dis 1989;48:672-6.

25 Alarcon-Segovia D, Deleze M, Oria CV, Sanchez-Guerrero J, Gomez-Pacheco L, Cabiedes J, et al. Antiphospholipid antibodies and the antiphospholipid syndrome in systemic lupus erythematosus. A prospective analysis of 500 consecutive patients. Medicine (Baltimore) 1989;68:35365.

26 Mok CC, Lau CS, Wong RWS. Risk factors for avascular necrosis in systemic lupus erythematosus. Br J Rheumatol 1998;37:895-900

27 Jones JP Jr. Intravascular coagulation and osteonecrosis. Clin Orthop 1992;277:41-53.
28 Lorache M, Ludot I, Thiechart M, Viguier G, Dromer C, Mazieres B. Histological appearance of the intra-osseous vessles of the femoral head in aseptic osteonecrosis of the hip, with or without antiphospholipid antibodies. Clin Rheumatol 1997;16:367-71.

29 Alijotas J, Argemi M, Barjuinero J. Kienbock's disease and antiphospholipid antibodies. Clin Exp Rheumatol 1990;8: 297-8.

30 Asherson RA, Liote F, Page B, Meyer O, Buchanan N, Khamashta MA, et al. Avascular necrosis of bone and antiphospholipid antibodies in systemic lupus erythematosus. J Rheumatol 1993;20:284-8.

31 Vela P, Batlle E, Salas E, Marco P. Primary antiphospholipid syndrome and osteonecrosis [letter]. Clin Exp Rheumatol 1991;9:545-6.

32 Seleznick MJ, Silverira LH, Espinoza LR. Avascular necrosis associated with anticardiolipin antibodies. J Rheumatol 1991;18:1416-17.

\section{NOVARTIS • ILAR RHEUMATOLOGY PRIZE}

In awarding this prize, both the International League of Associations for Rheumatology (ILAR) and NOVARTIS wish to emphasise that progress in the field of rheumatology can only take place through close cooperation between academic institutes, scientific societies, clinical rheumatologists, hospitals, and research based pharmaceutical companies.

The prize is to the value of SFr 60000 and will be awarded during the opening ceremony of the International Congress of Rheumatology in Edmonton, Canada, in August 2001. The deadline for submission of entries is 15 July 2000.

Those interested should contact the Prize Secretariat, who will be pleased to send rules and application forms.

Requests should be addressed to:

NOVARTIS • ILAR • Rheumatology Prize

c/o Meritus Communications

Eden House, Enterprise Way, Edenbridge, Kent TN8 6HF, UK

Fax: +44(0) $1732867680 \bullet$ Email: meritus.uk@virgin.net 